\title{
Conceptual Framework: Development of Interactive Reading Malay Language Learning System (I-ReaMaLLS)
}

\author{
Nurulisma Ismail $^{1, *}$, Rasimah Che Mohd Yusoff ${ }^{2}$, and Mohamad Umar Jiman ${ }^{1}$ \\ ${ }^{1}$ School of Computer \& Communication Engineering (SCCE), Universiti Malaysia Perlis (UniMAP), c/o School of Manufacturing \\ Engineering Complex, First Floor, Pauh Putra Campus, 02600 Arau, Perlis, Malaysia \\ ${ }^{2}$ Advanced Informatics School, Universiti Teknologi Malaysia, Jalan Sultan Yahya Petra, 54100 Kuala Lumpur, Malaysia
}

\begin{abstract}
Reading is very important to access knowledge. Reading skills starts during preschool level no matter of the types of languages. At present, there are many preschool children who are still unable to recognize letters or even words. This leads to the difficulties in reading. Therefore, there is a need of intervention in reading to overcome such problems. Thus, technologies were adapted in enhancing learning skills, especially in learning to read among the preschool children. Phonological is one of the factors to be considered to ensure a smooth of transition into reading. Phonological concept enables the first learner to easily learn reading such to learn reading Malay language. The medium of learning to read Malay language can be assisted via the supportive of multimedia technology to enhance the preschool children learning. Thus, an interactive system is proposed via a development of interactive reading Malay language learning system, which is called as I-ReaMaLLS. As a part of the development of I-ReaMaLLS, this paper focus on the development of conceptual framework in developing interactive reading Malay language learning system (I-ReaMaLLS). I-ReaMaLLS is voice based system that facilitates the preschool learner in learning reading Malay language. The conceptual framework of developing I-ReaMaLLS is conceptualized based on the initial study conducted via methods of literature review and observation with the preschool children, aged $5-6$ years. As the result of the initial study, research objectives have been affirmed that finally contributes to the design of conceptual framework for the development of I-ReaMaLLS.
\end{abstract}

\section{Introduction}

Education is one of the biggest concerns of a government in developing human resource that can contribute to the nation. The education at preliminary level is a very important phase for children because via preschool education, children will be exposed to a wider learning environment compared to the children that are home-schooled. In the process of teaching and learning Malay language, there are three (3) skills that have to be mastered by the children which are reading, writing and oral skills. Reading is a key to all knowledge [1]. Therefore, it is very important for children to be able to read, especially in Malay language as the first language in Malaysia. At the preliminary education level in most of public preschools in Malaysia, Malay language plays an important role in delivery knowledge to the preschool children, followed by English language. However, despite the importance of reading skills, a lot of research shows that the first preschool learner who is new to learn reading found difficulties to learn reading via only recognizing the alphabet letters. The method to learn reading is easily for the preschool learner to learn reading Malay language is via recognizing the sound of the alphabet letters. This learning method is known as phonological [2], [3], [4], [5]. Learning to read involves the children's capabilities such as attention, memory, knowledge of alphabet letters and knows how to relate the word in a given context. However, during learning a learner tends to lost focus, feeling bored, and difficult to conduct tasks without assistance. Therefore, an interactive learning system can be developed since multimedia technology can be applied to improve reading skills of the preschool learner [6], [7], [8]. Thus, this research aims to propose the conceptual framework in developing interactive reading Malay language learning system (I-ReaMaLLS).

\section{Related works}

\subsection{Phonic method}

One of the methods that are commonly used in teaching preschool children to read is by using phonic method. Phonic method teaches the children to recognize letter with its associated sound and not the name of the letter. This method has been introduced in Brunei a few years ago to the preschool children. It had a significant difference between the old methods of teaching the children. The implementation of phonic method at preschool level in Brunei enabled the children learns to read faster than the traditional way which was teaching

*Corresponding author: nurul@unimap.edu.my 
children by using syllable. This method enabled the children read newspaper without the help of teachers [9].

\subsection{Multimedia System}

In the millennium era, it is very important to turn the traditional way of learning into computer-assisted learning mechanism. The Theory of Cognitive states that learning will be easier to be conducted through recognition and observation of objects via a medium such as visual and sound, which is referring to the multimedia elements compared to the old traditional way that depends only on printed materials such as books. Multimedia is the combination of various media: text, graphics, animation, images and video. It is a new technology that benefits to the education field: to ease learning, to give motivation and to give a more effective explanation. Therefore, almost all levels of learning institution in Malaysia implements the interactive learning system that involved almost all the human sensory [10]: visual, audio, and tactile senses.

In order to develop a reading learning system for preschool children, the usages of multimedia have to be fully utilized. A developed system for the children should contain a story element, drawing, designing something, writing a story with the help of images, the understanding of a computer, to develop thinking and to enhance their vocabulary. In addition, the developed system enables the children learning on themselves or in a group. Due to this, a sufficient scaffolding of the developed system should be embedded as the assistive tools for the children's learning. For example, children who have difficulties in understanding a text relies on the articulation tool in a form of audio. Further, the concept of reflection is another significant element in developing an interactive learning system for the preschool children. Every single interaction of the children with the system should have feedbacks to enable the children understand on the learning activities [11].

\section{Method}

The development of I-ReaMaLLS complies with the initial study in order to understand the problem occurred in the learning reading process among the preschool children. The initial study has been conducted in two (2) methods: literature review and observation. Literature review has been conducted with reviews on few of journals articles that related to the method of teaching and learning reading for the preschool children. The observational method was conducted to identify the teaching and learning process in reading Malay language among the preschool children.

\subsection{Review of Literature}

A few reviews have been conducted in order to understand the method of teaching and learning reading for the preschool children. Reading process is a difficult phase but an important task for children [12]. This is because reading involves the children's capabilities: attention, memory, knowledge (of letters) and knows how to relate the word in a given context. The main problem for children to learn is they tend to lost focus, become bored, and they cannot begin a new task without assistance. Therefore, there is a requirement to develop an interactive learning system in order to provide a fun method of learning for the children. The following subsections highlight on the results of the conducted literature review based on few of journals articles.

\subsubsection{Results of literature review}

\section{- Phonic method}

Phonic method is used to assist the children recognize letter by matching the letter with its associated sound. For example, the letter " $a$ " is pronounced with 'aa...', the letter "s" is pronounced with 'ss...', and the letter " $z$ " is pronounced with ' $z z . .$. '. Once the children knew the relations between the letter and its pronunciation, they were taught to form a syllable such as 'ba', 'ta', 'cu', and 'ka'. The syllables then were combined to form a word. The word was not formed by spelling the letter, but via combining the syllable that they have learnt. For example, to read 'bata', the children directly combined the syllable 'ba' + 'ta' without spelling each of the letters.

\section{- Development of application system for children: functionality and usability}

Developing an application system for the children has to consider on two (2) factors: usability and functionality of the developed system. Functionality means the system must function for the specific requirements [13] meanwhile usability means the needs of the system to be friendly, that is easy to be used [14]. Based on the literature review conducted in [13-14], the factors of functionality and usability were very important in the development of an application system to assure that the developed system is well functioned to confirm the usability of the developed system meets the requirements of learning for the children. Lacking in functionality elements leads to the problems in usability of the developed system. For example: the children cannot interact very well with the system because some features of the system were not fully facilitated the requirements of learning environment for the children. Therefore, the issues of functionality and usability are very important elements to be considered in the development of IReaMaLLS.

\section{- Advantages of multimedia in the development of I-ReaMaLLS}

Based on the research conducted [11], claimed that multimedia can stimulate almost all human sensory. Thus, it is crucial to apply multimedia elements in the reading learning system for the preschool children since 
it is able to expand on the imagination, creativity, fantasy as well as the emotion of the children.

Further, the previous research conducted [13] relied on the observational of the emergent literacy among the preschool children. There were two (2) mechanism used: printed book and electronic book. The results showed that the reading accuracy rate of using electronic book was higher compared to the printed book.

Therefore, it concludes that the use of multimedia learning system can facilitate more effectively in children's reading learning compared to the traditional method: spelling syllable and printed book.

\subsection{Observation}

Observational method is the action or process of observing something or someone carefully in order to gain information. In this research, the observational method was applied in the initial study to understand the process of the preschool children in learning to read in Malay language.

\subsubsection{Results of observation}

Observational method was conducted in one of preschool in northern state of Malaysia, Perlis. The observation involved participation of one (1) preschool child aged 5 years who is capable to understand instructions, with the help of one (1) teacher. The preschool child read fluently a printed story book that was written in Malay language. During the reading process, it has been noticed that the child applied the phonic method. She finished reading the story book within a short period.

Parallel to the observation process, the teacher claimed that phonic method is more efficient in teaching the children to read. The children can easily recognize the letters together with the sound of each letters. Once the children clearly understand the pronunciation of each letters, they can easily pronounce the combination letters that finally make up a complete word then a sentence.

In addition, based on the teacher's feedback regarding to learning to read can be implemented in both languages: Malay and English language. There are requirements for two-way interactive of multimedia learning system to motivate the preschool children to learn reading in both languages. At the moment, most of the preschool in northern state of Malaysia used the oneway interactive of multimedia learning system that based on the synchronous method of learning. Sometimes, the children feel bored when the playing multimedia learning system took a long time to finish the syllabus of reading learning.

Therefore, it concludes that the use of phonic method is easy to help the children to learn reading. The reading learning system should integrate the multimedia elements to motivate the children in learning to read. This research focus on the development process of reading learning system in Malay language that applies the phonic method with the integration of voice-based medium. The learning method used would be the asynchronous learning method with approach of the two- way interaction medium: interaction between the preschool children and the reading learning system. This method will be applied in order to achieve the objective of the research to develop an assistive tool to help the preschool children in learning to read in Malay language.

\section{Proposed Conceptual Framework for Development of I-ReaMaLLS}

As the problem statement has been identified through the literature review and observation conducted, the following research objectives has been formed: (i) to develop a voice based application system as an assistive tool that facilitates the preschool children in learning to read in Malay language (ii) to perform the usability testing of the prototype of I-ReaMaLLS.

Based on the stated objectives, this research will be conducted as a qualitative research. It is to develop a reading Malay language learning system for the preschool learners aged $5-6$ years. It can be an assistive tool for the preschool children learning reading in Malay language.

The development of I-ReaMaLLS highlights on the usability principles. The research methods considers the research methods in human-computer interaction field, where as the system development focus on software engineering methods that relies on the process of iteration-evolution life cycle based on user-oriented approach. In order to develop I-ReaMaLLS, also focus on the needs of the preschool children in learning to read Malay language via voice-based medium that considered on the Theory of Cognitive [15]. This theory considered a few cognition processes of the preschool children during learning process via voice-based medium of interaction with I-ReaMaLLS. The cognition processes that are taken into consideration for this research include: attention; perception and recognition; memory; and learning. This is according to the usage of voicebased medium of interaction that involved the interaction process between the preschool children with IReaMaLLS. The interaction process relied on the voice command spoken by I-ReaMaLLS to the children during learning process to read Malay language. The children give feedback to the I-ReaMaLLS via using the tactile keyboard.

The research involves participatory of the preschool children aged $5-6$ years who are capable to understand instructions. The participatory of users contributes in two (2) parts of the development process for I-ReaMaLLS. There are:

i. First Part - the initial stage of the research in determining the requirements needed for the development of I-ReaMaLLS.

ii. Second Part - the final stage of the research, which is the testing phase of I-ReaMaLLS. This is to determine the functionality and usability of the system fulfilled the children's requirement in learning to read Malay language. The testing are categorized into two 
(2) stages: formative and summative evaluation.

The formative evaluation involves the experts in design and development phase in three (3) iteration cycles. At this stage, the user interfaces and interaction activities of I-ReaMaLLS are based on the cognitive processes of the preschool children to easily and efficiently learning to read Malay language.

The whole development process of I-ReaMaLLS has been conceptualized via the conceptual framework as illustrated in Figure 1. The framework is divided into three (3) phases for the research to be conducted systematically. (i) Phase 1 System Requirements and Specifications, (ii) Phase 2 Development of Interactive Reading Malay Language Learning System (IReaMaLLS), and (iii) Phase 3 Evaluation of Interactive Reading Malay Language Learning System (IReaMaLLS).

Phase 1 involves the initial study to identify the research problem and requirement specification of the IReaMaLLS. This process consists of two (2) parts: (i) Preliminary Study 1, and (ii) Preliminary Study 2. The Preliminary Study 1 involves the process of literature study in order to understand concepts, theories, and principles that related and supported to the development of I-ReaMaLLS for the children to easily and efficiently learning to read Malay language.

Phase 2 involves the process of development for IReaMaLLS. The process consists of the process of analysis the requirements and specifications of the realated technology that to be applied in the development of I-ReaMaLLS. User-oriented approach is applied in order to identify the needs of the preschool children in learning to read Malay language. The development of IReaMaLLS is based on the software engineering methodology that relies on the process of iterationevolution. In addition, a development framework is illustrated by a model named as the Iterative-Evolution System Development Life Cycle for Interactive Reading Malay Language Learning System (IE-SDLC-IReaMaLLS). This model is based on the three (3) cycles of iteration process of developing prototype: the Throwaway Prototype Model, Prototype Model and Evolutionary Prototype Model. These models are supported by the formative evaluation with the expert. The formative evaluation is based on the functionality testing of I-ReaMaLLS.

Phase 3 is the evaluation phase for the I-ReaMaLLS. It involves the summative evaluation which relies on the usability testing. The usability testing is based on four (4) constructs: Learnability, Efficiency, Usability Error, and satisfaction [16]. The summative evaluation is categorized into two (2) stages: Pilot Study and Field Study. It involves with the end user of I-ReaMaLLS: the preshool children aged $5-6$ years.

\section{Conclusions}

This research objective is to develop and evaluate the IReaMaLLS as an assistive tool for the preschool children to learn reading Malay language. The development of IReaMaLLS is based on user-oriented approach. In order to achieve the research objectives, the development of IReaMaLLS is illustrated via Figure 1, the conceptual framework that based on a model: the IterativeEvolution System Development Life Cycle of IReaMaLLS (IE-SDLC-ReaMaLLS. The evaluation of IReaMaLLS has two (2) categories: Formative Evaluation (Expert) on the functionality testing of I-ReaMaLLS, and Summative Evaluation on the usability testing (Pilot and Field Study with the preschool children). The usability testing relies on four (4) constructs: Learnability, Efficiency, Usability Error and Satisfaction. Based on the illustrated conceptual framework can lead to a clear of development process for I-ReaMaLLS as the assistive tool for the preschool learner to learn reading Malay language.

\section{References}

[1] Z. Tasir and C. Likun, "Perisian Multimedia bagi Pembelajaran Mengenal Huruf dan Nombor untuk Pelajar Prasekolah", pp. 1-18, 2005.

[2] A. Castles and M. Coltheart, "Is there a causal link from phonological awareness to success in learning to read?," Cognition, vol. 91, no. 1, pp. 77-111, Feb. 2004.

[3] C. M. Fletcher-Flinn and G. B. Thompson, "Learning to read with underdeveloped phonemic awareness but lexicalized phonological recoding: A case study of a 3-year-old," Cognition, vol. 74, no. 2, pp. 177-208, 2000.

[4] M. Melby-Lervåg, S.-A. H. Lyster, and C. Hulme, "Phonological skills and their role in learning to read: a meta-analytic review.," 2012.

[5] C. Hulme, C. Bowyer-Crane, J. M. Carroll, F. J. Duff, and M. J. Snowling, "The causal role of phoneme awareness and letter-sound knowledge in learning to read: Combining intervention studies with mediation analyses," Psychol. Sci., vol. 23, no. 6, pp. 572-577, 2012.

[6] M. Neo, T.-K. Neo, and X.-L. Tai, "A constructivist approach to learning an interactive multimedia course: Malaysian students' perspectives," Australas. J. Educ. Technol., vol. 23, no. 4, 2007.

[7] N. A. Mukti and S. P. Hwa, "Malaysian perspective: Designing interactive multimedia learning environment for moral values education," J. Educ. Technol. Soc., vol. 7, no. 4, 2004.

[8] S. Nusir, I. Alsmadi, M. Al-Kabi, and F. Sharadgah, "Studying the impact of using multimedia interactive programs at children ability to learn basic math skills," Acta Didact. Napoc., vol. 5, no. 2, p. 17, 2012.

[9] Y. Othman, A. M. Daud, A. Othman, D. S. A. P. Mohiddin, and M. M. Sulaiman, "Pelaksanaan pengajaran membaca menggunakan kaedah fonik peringkat prasekolah di Brunei Darussalam", pp. 93-109.

[10] A. Esa, B. Mohamad, and S. N. Mukhtar, "Peranan Multimedia di dalam Pembelajaran Kanak-kanak", November, pp. 18-20, 2007. 
[11] Munir and Halimah Badioze Zaman. "Aplikasi Multimedia dalam Pendidikan”. Jurnal Bahagian Teknologi Pendidikan. Bil 1. Kementerian Pendidikan, Kuala Lumpur, Malaysia. 1999.

[12] D. M. Popovici, C. Buche, R. Querrec, and F. Harrouet, "An Interactive Agent-based Learning Environment for Children", Cyberworlds, 2004 Int. Conf., pp. 233-240, 2004.

[13] Y. Huang, T. Liang, Y. Su, and N. Chen, "e-Book Learning System for Elementary School Students", no. 60, pp. 703-722, 2012.

[14] E. H. Sibley, "Functionality and Usability".

[15] Sharp, H., Rogers, Y. \& Preece, J. Interaction Design: Beyond Human Computer Interaction. John Wiley \& Sons Ltd. 2006.

[16] Nielsen, J. Usability Engineering. Morgan Kaufmann. 1993. 


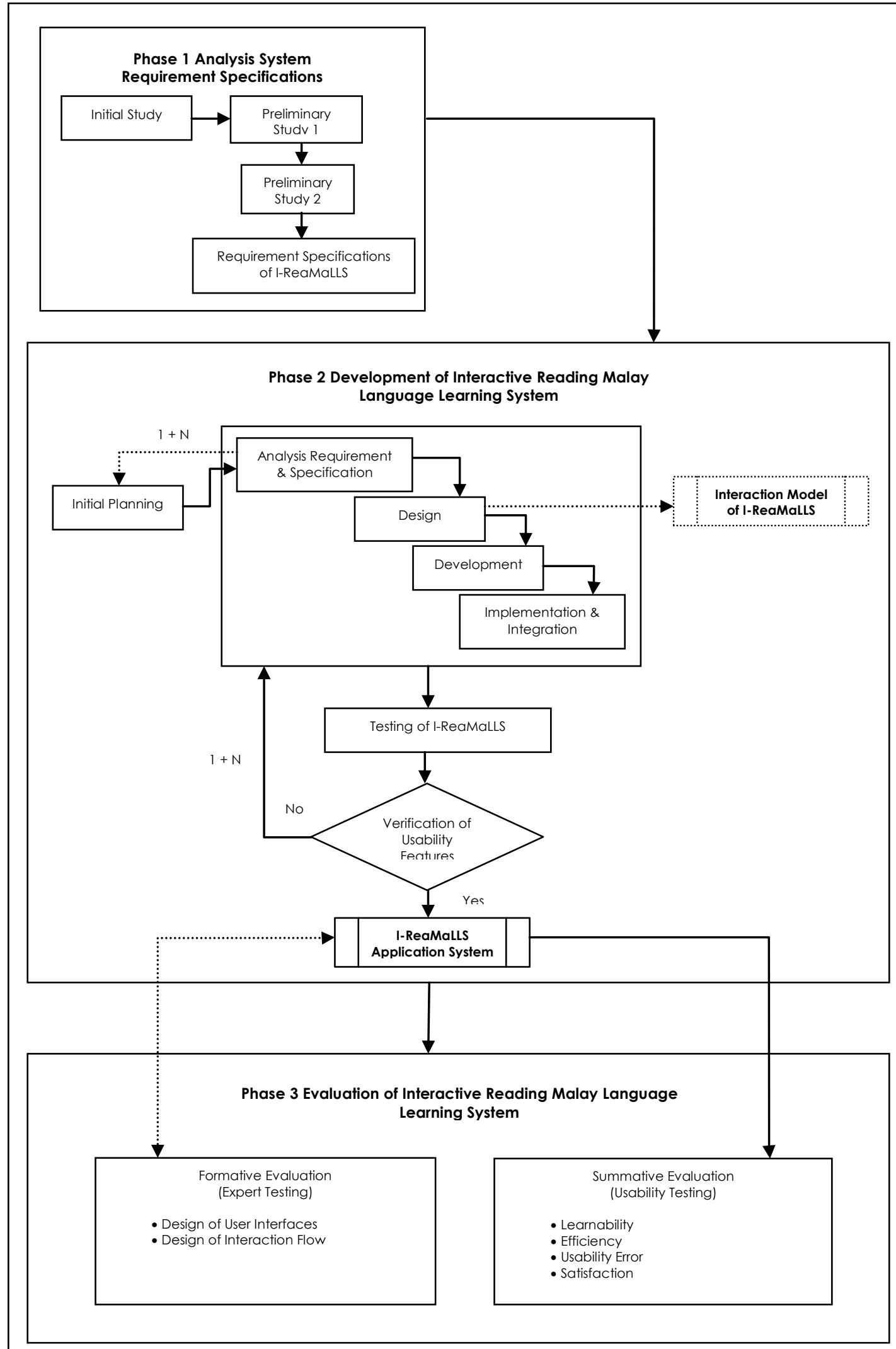

Figure.1 Conceptual Framework of Research on the Development of I-ReaMaLLS

\footnotetext{
Corresponding author: nurul@unimap.edu.my
} 